\title{
The determinants of Chinese outward foreign direct investment
}

Peter J Buckley, L Jeremy

Clegg, Adam R Cross, Xin Liu, Hinrich Voss and Ping Zheng
Journal of International Business Studies (2009) 40, 353-354.

doi: 10.1057/jibs.2008.102

Correction to: Journal of International Business Studies (2007) 38, 499-518. doi: 10.1057/Palgrave.jibs.8400277

Owing to a production error, some values in Table 6 of this article were incorrect. Specifically, a number of negative values for the variables LPATENT, LPOLI, LIMP, LDIS and LINFDI were presented without the necessary minus signs. A corrected version of Table 6 is presented below. 
Table 6 Results for the determinants of Chinese ODI

\begin{tabular}{|c|c|c|c|c|c|c|}
\hline & $\begin{array}{l}\text { POLS } \\
(1)\end{array}$ & $\begin{array}{l}\text { REs } \\
\text { (2) }\end{array}$ & $\begin{array}{c}\text { REs } 1984-1991 \\
\text { (3) }\end{array}$ & $\begin{array}{c}\text { REs } 1992-2001 \\
\text { (4) }\end{array}$ & $\begin{array}{c}\text { RES OECD } \\
\text { (5) }\end{array}$ & $\begin{array}{c}\text { REs non-OECD } \\
\text { (6) }\end{array}$ \\
\hline \multirow[t]{2}{*}{$\operatorname{LGDP}(\mathrm{H} 1 \mathrm{a})$} & 0.3463 & 0.3448 & 0.5085 & 0.2448 & 0.6674 & 0.3472 \\
\hline & $(0.1249)^{\star * *}$ & $(0.1640)^{\star *}$ & $(0.2787)^{*}$ & $(0.2009)$ & $(0.3650)^{*}$ & $(0.2238)$ \\
\hline \multirow[t]{2}{*}{ LORE $(\mathrm{H} 2)$} & 0.1713 & 0.1447 & 0.1039 & 0.2253 & -0.0138 & 0.1820 \\
\hline & $(0.0742)^{\star \star}$ & $(0.1057)$ & $(0.1654)$ & $(0.1206)^{*}$ & $(0.3906)$ & $(0.1144)$ \\
\hline \multirow[t]{2}{*}{ LPATENT $(\mathrm{H} 3)$} & -0.0223 & -0.0363 & 0.0794 & -0.0516 & -0.0752 & -0.0262 \\
\hline & $(0.0309)$ & $(0.0359)$ & $(0.0605)$ & $(0.0439)$ & $(0.0773)$ & $(0.0447)$ \\
\hline \multirow[t]{2}{*}{ LPOLI (H4) } & -2.4762 & -1.7997 & -0.7347 & -2.6308 & -1.8973 & -1.4560 \\
\hline & $(0.5822)^{\star \star \star}$ & $(0.6974)^{\star \star}$ & $(1.0846)$ & $(0.9750)^{\star \star \star}$ & $(1.8807)$ & $(0.8903)$ \\
\hline \multirow[t]{2}{*}{$C P(\mathrm{H} 5)$} & 1.4779 & 1.4929 & 1.4520 & 1.5338 & 2.0464 & 0.8414 \\
\hline & $(0.2588)^{\star \star *}$ & $(0.4276)^{\star * \star}$ & $(0.6059)^{\star *}$ & $(0.4634)^{\star \star \star}$ & $(0.8415)^{\star *}$ & $(0.6563)$ \\
\hline \multirow[t]{2}{*}{ TD92 (H6) } & 0.6595 & 0.6961 & & 0.8033 & 0.9489 & 0.4104 \\
\hline & $(0.2698)^{\star \star}$ & $(0.2534)^{\star \star \star}$ & & $(0.3002)^{\star \star \star}$ & $(0.3178)^{\star \star \star}$ & $(0.4021)$ \\
\hline \multirow[t]{2}{*}{ LERATE $(\mathrm{H7})$} & 0.0471 & 0.0688 & 0.1032 & 0.0246 & 0.2319 & 0.0142 \\
\hline & $(0.0337)$ & $(0.0463)$ & $(0.0638)$ & $(0.0618)$ & $(0.1866)$ & $(0.0540)$ \\
\hline \multirow[t]{2}{*}{ LINF (H8) } & 0.2406 & 0.1891 & 0.4664 & 0.1323 & 0.3487 & 0.1320 \\
\hline & $(0.0628)^{\star \star \star}$ & $(0.0734)^{\star \star}$ & $(0.1167)^{\star \star \star}$ & $(0.0896)$ & $(0.1579)^{\star *}$ & $(0.0914)$ \\
\hline \multirow[t]{2}{*}{$\operatorname{LEXP}(\mathrm{H} 9)$} & 0.6934 & 0.6153 & 0.2731 & 0.8275 & 0.4062 & 0.8375 \\
\hline & $(0.1084)^{\star \star \star}$ & $(0.1291)^{\star \star \star}$ & $(0.2094)$ & $(0.1803)^{\star \star \star}$ & $(0.2053)^{\star \star}$ & $(0.1964)^{\star \star \star}$ \\
\hline \multirow[t]{2}{*}{ LIMP (H10) } & -0.2601 & -0.2544 & -0.3087 & -0.3098 & -0.1914 & -0.3677 \\
\hline & $(0.0931)^{\star \star *}$ & $(0.1027)^{\star \star}$ & $(0.2061)$ & $(0.1204)^{\star \star}$ & $(0.1898)$ & $(0.1374)^{\star * *}$ \\
\hline \multirow[t]{2}{*}{ LDIS (H11) } & 0.1905 & 0.1554 & -0.9266 & 0.2885 & 0.7452 & 0.0171 \\
\hline & $(0.2035)$ & $(0.2972)$ & $(0.4794)^{*}$ & $(0.3400)$ & $(0.7360)$ & $(0.4259)$ \\
\hline \multirow[t]{2}{*}{ LINFDI (H12) } & 0.0927 & 0.0510 & 0.3294 & -0.0589 & -0.1181 & 0.1218 \\
\hline & $(0.0886)$ & $(0.1244)$ & $(0.1562)^{\star \star}$ & $(0.0439)$ & $(0.2480)$ & $(0.1546)$ \\
\hline$N$ & 402 & 402 & 116 & 286 & 198 & 204 \\
\hline LM test & $\chi^{2}(1)=15.43^{* * *}$ & & & & & \\
\hline Adj. $R^{2}$ & 0.3642 & 0.6019 & 0.6142 & 0.6024 & 0.5763 & 0.6737 \\
\hline
\end{tabular}

Notes: Standard errors are in parentheses.

${ }^{* * *},{ }^{* *}$ and ${ }^{*}$ indicate that the coefficient is significant at the 1,5 and $10 \%$ levels, respectively. 